\title{
Mechanical Behavior of Multiwalled Carbon Nanotube Reinforced 7075 Aluminum Alloy Composites Prepared by Mechanical Milling and Hot Extrusion
}

\author{
Eduardo Uriza-Vega ${ }^{a}$,Caleb Carreño-Gallardo ${ }^{a *} \mathbb{C}$, \\ Claudia López-Meléndez ${ }^{b}$ Eduardo Cuadros-Lugo ${ }^{a}$, Raúl Pérez-Bustamante ${ }^{c}$, \\ Ernesto Ledezma-Sillas ${ }^{a}$, Jose Martin Herrera-Ramirez ${ }^{a}$ \\ ${ }^{a}$ Centro de Investigación en Materiales Avanzados (CIMAV), Laboratorio Nacional de Nanotecnología- \\ Chihuahua. Miguel de Cervantes No. 120, C.P. 31136, Chihuahua, México. \\ ${ }^{b}$ Universidad La Salle Chihuahua. Prol. Lomas de Majalca No. 11201, C.P. 31020 Chihuahua, México. \\ ${ }^{c}$ CONACYT-Corporación Mexicana de Investigación en Materiales S.A. de C.V. (COMIMSA), Ciencia Y \\ Tecnología 790, Fracc. Saltillo No. 400, C.P. 25290, Saltillo, Coahuila, México.
}

Received: October 03, 2018; Revised: November 09, 2018; Accepted: January 08, 2019

\begin{abstract}
In this paper, multiwalled carbon nanotubes (MWCNTs) were synthesized by spray pyrolysis to be used later as material reinforcement in the production of MWCNTs/A17075 aluminum composites. Both, MWCNTs and MWCNTs/A17075 composites were microstructurally and mechanically characterized. Scanning electron microscopy (SEM) analysis shows MWCNTs formed by multiple layers rolled on themselves forming a tube shape with lengths up to $1300 \mu \mathrm{m}$ and diameters ranging from 55 to $120 \mathrm{~nm}$. MWCNTs were added to the aluminum matrix in different concentrations up to $3.0 \mathrm{wt} \%$. Their dispersion in the aluminum matrix was carried out by ultrasonic/methanol method followed by high-energy mechanical milling process. The effect of MWCNTs on the morphology and mechanical behavior of composites were evaluated. Results indicate that a homogeneous dispersion of CNTs was obtained as a consequence of the dispersion routes used in the production of composites, observing no damage on their morphology. The mechanical behavior of the composites shows a noticeable improvement for MWCNTs concentrations above $2.0 \mathrm{wt} \%$, with ductility similar to that found in the literature for the A17075 commercial alloy.
\end{abstract}

Keywords: spray pyrolysis, mechanical milling, mechanical properties, metal matrix composites.

\section{Introduction}

The most important methods developed to produce single and multiwalled carbon nanotubes include electric arc discharge, laser ablation and catalyzed chemical vapor deposition $(\mathrm{CCVD})^{1}$. CCVD has been reported to be a lowcost method in producing multiwalled carbon nanotubes (MWCNTs) and nanotube bundles. Spray pyrolysis is a type of CCVD method in which it is possible to produce large amounts of well graphitized, multiwalled carbon nanotubes at low cost, with the promise of industrial up-scaling ${ }^{2}$.

Typically, the MWCNTs synthesis involves the spray of a metallocene/hydrocarbon solution in a furnace with a flow of inert or slightly reductive gas ${ }^{3}$. Aligned multiwalled carbon nanotubes have been obtained by pyrolysis of acetylene gas mixed with argon ${ }^{4}$ and the length of the obtained nanotubes were $2000 \mu \mathrm{m}$ when iron pentacarbonyl was used as catalyst ${ }^{5}$.

Carbon nanotubes (CNTs) have emerged as an important class of new materials for structural engineering and functional applications due to their high mechanical strength, electrical and thermal conductivities ${ }^{6-8}$. Their high aspect ratio and intrinsic properties make CNTs the most effective reinforcement to produce composite materials. The interest

*e-mail: caleb.carreno@ cimav.edu.mx in using these nanotubes as reinforcement in metal-matrix composites is encouraged by their successful incorporation into polymer-matrix composites of high performance ${ }^{9}$. Nevertheless, incorporating CNTs in metal-matrices is rather difficult due to several reasons, such as their high tendency to agglomerate into clusters, poor dispersion ability in the metal-matrix, poor wettability of carbon by molten metal due to a large difference of surface tensions and the formation of an interfacial reaction product.

The applications of CNTs in aluminum metal composites (AMCs) for overcoming the performance limits of conventional materials have been increasingly reported ${ }^{7,10,11}$. This is due to the CNTs capabilities for an effective load transfer from the aluminum matrix during mechanical testing, product of their homogeneous dispersion into the aluminum matrix. Depending on the effectivity of the dispersion technique, a positive effect on the mechanical properties of AMCs reinforced with CNTs has been reported in a wide range of CNTs contents ${ }^{12,13}$. Previous studies have concluded that a good dispersion of CNTs in the matrix is very critical for obtaining high strengthening in the final composite ${ }^{14,15}$. However, owing to the strong van der Waals force of attraction among CNTs, large size and density discrepancy between CNTs and matrix, as well as high consolidation temperature, 
the incorporation of uniformly dispersed CNTs into AMCs without losing their unique properties is rather difficult. Therefore, the enhancement efficiency of CNTs in AMCs has not been fully exploited. Many attempts, such as high pressure torsion ${ }^{16}$, friction stir processing ${ }^{17}$, flake powder metallurgy ${ }^{18,19}$ and nanoscale dispersion ${ }^{20}$, have been made to deal with CNTs dispersion in aluminum matrix composites. In past years, a group reported that the ball milling for the in situ synthesis of Al powders/CNTs composites is a highly effective and economic route to improve the dispersion of CNTs in AMCs ${ }^{21,22}$. In this paper, MWCNTs-reinforced aluminum matrix composites with different MWCNTs content $(0-3 \mathrm{wt} \%)$ were produced via powder metallurgy route (ball milling process), including the previous synthesis of MWCNTs by in situ spray pyrolysis. The influence of CNTs content on the powder size and the integration of CNTs were systematically investigated.

\section{Experimental Procedure}

\subsection{MWCNTs production by spray pyrolysis}

The spray pyrolysis process ${ }^{23}$ applied to produce MWCNTs is illustrated in Figure 1, where a quartz tube was used as a solution atomizer by an injection syringe system. The overall tube dimensions had an internal diameter of 9 $\mathrm{mm}$ and a length of $500 \mathrm{~mm}$. A cylindrical furnace (Thermo Scientific) with a high precision temperature controller $\left( \pm 1^{\circ} \mathrm{C}\right)$ was used to heat the quartz tubing. The solution feed time was kept constant for $15 \mathrm{~min}$ for all experiments; $50 \mathrm{~mL}$ of toluene (J.T. Baker, $100 \%$ purity) and $1 \mathrm{~g}$ of ferrocene (Aldrich, 98\% purity) were placed into a glass container. Argon (Praxair, $99.99 \%$ purity) was used as the carrier gas; a mass flow controller fixed the flow rate at $17 \mathrm{~cm}^{3} / \mathrm{s}$. An argon/toluene/ferrocene mixture was fed into the quartz tubing after the furnace temperature was set at $800^{\circ} \mathrm{C}$.
Once the quartz tube was exposed to spray pyrolysis, the furnace was cooled down under an argon flow until it reached room temperature. After processing, a MWCNTs black film was formed on the inner surface of the quartz tubing, which was mechanically removed with a brush. Some pieces of the quartz tube were broken and analyzed by scanning electron microscopy (SEM) before removing the black film, in order to observe how the MWCNTs were attached to such tube. A field emission scanning electron microscope (FESEM, JEOL JSM 7401F) and a high-resolution transmission electron microscope (HRTEM, Hitachi 7700) were employed to characterize the as-synthesized multiwalled carbon nanotubes.

\subsection{Fabrication of multiwalled carbon nanotubes/7075 aluminum alloy composites}

The A17075 alloy and the MWCNTs previously prepared in this work were used as raw materials to synthesize the composites. Initially, aluminum alloy swarfs were produced by machining a bar-shaped commercial alloy. The machined metal swarfs were mixed with MWCNTs at different concentrations $(0.0,0.5,1.0,1.5,2.0,2.5$ and $3.0 \mathrm{wt} \%)$; afterwards, the mixtures were sonicated in isopropyl alcohol for $30 \mathrm{~min}$ to obtain a homogeneous dispersion of the constituents, and finally dried with a heat gun (Figure 2). After drying, the mixtures were subjected to mechanical milling in a highenergy horizontal attritor mill (ZOZ CM01 Simoloyer); container and milling media were made from hardened steel. A ball to powder ratio of 20:1 was used in all runs. In order to avoid excessive welding of the powders, methanol was added to the milling runs. Argon flow was used as the milling atmosphere and the milling time was set to $5 \mathrm{~h}$. The morphology and size of the as-milled powders, as well as the dispersion of the reinforcement into the matrix, were analyzed by SEM using a Hitachi SU3500 microscope.

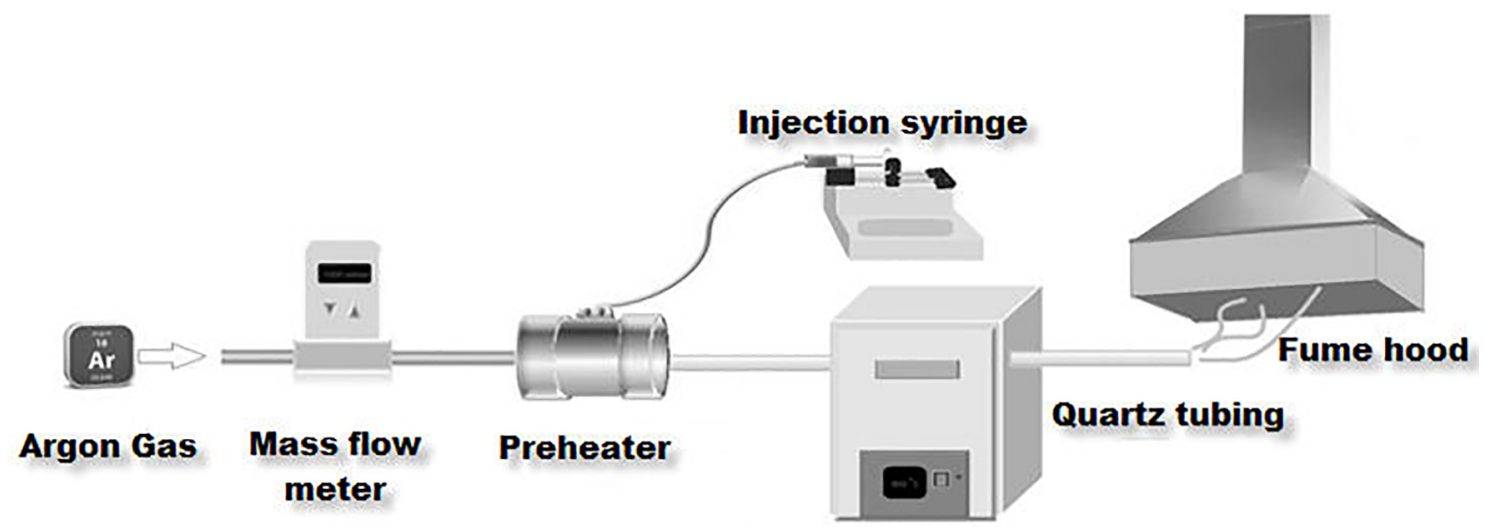

Cylindrical furnace

Figure 1. Schematic of the experimental setup to synthesize MWCNTs. 

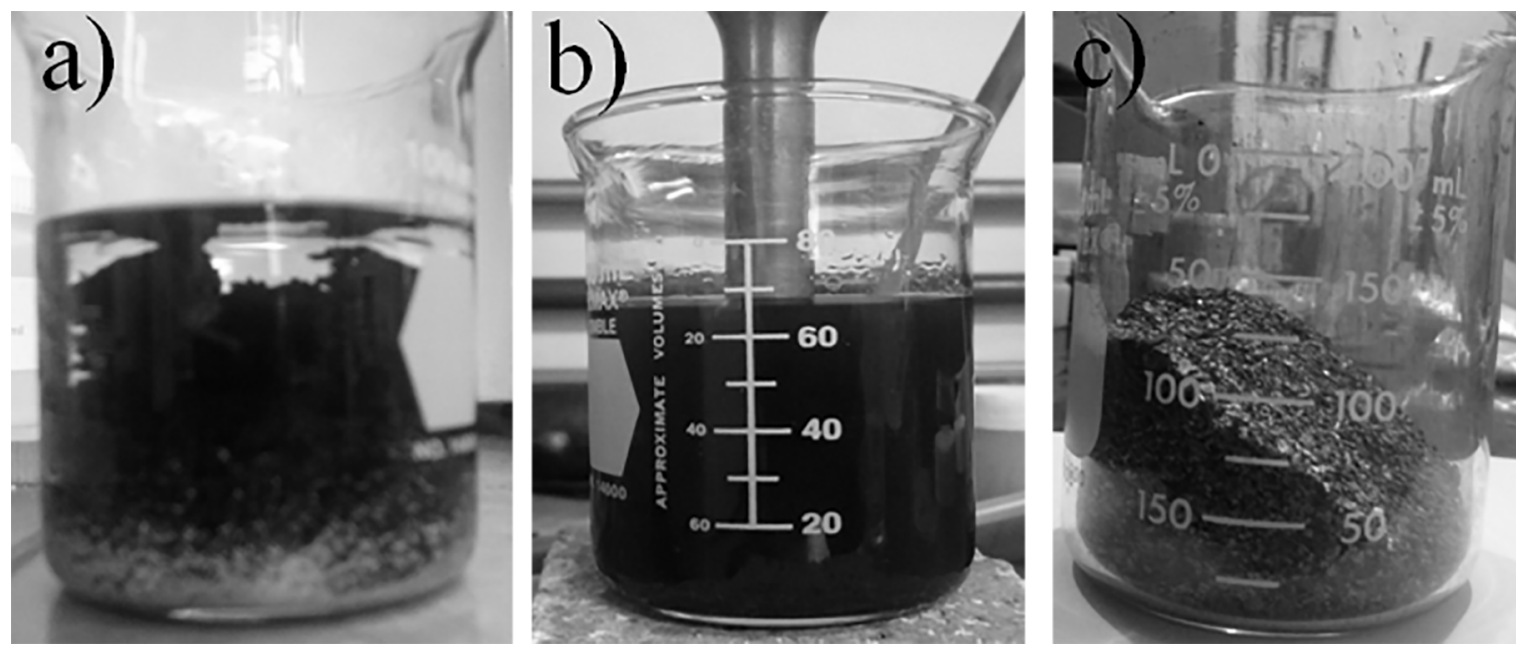

Figure 2. Ultrasonic dispersion of the A17075/MWCNTs mixture: a) before and b) during the evolution of the ultrasound irradiation, and c) after the drying process.

After fabrication the as-milled products were cold compacted by an axial load in a $45 \mathrm{~mm}$-diameter, lubricated, tool-steel die with pressure of $\sim 60$ Ton, followed by pressureless sintering preheat at $280^{\circ} \mathrm{C}$ held for $1 \mathrm{~h}$ and then increased at $550^{\circ} \mathrm{C}$ during $3 \mathrm{~h}$ under vacuum $(\sim 1$ Torr). Finally, the sintered samples were held at $500^{\circ} \mathrm{C}$ for $30 \mathrm{~min}$ and then hot extruded into $10 \mathrm{~mm}$-diameter rods; an extrusion ratio of 16 was used for all composites.

\subsection{Mechanical evaluation of multiwalled carbon nanotubes/7075 aluminum alloy composites}

The mechanical evaluation of composites was carried out at room temperature by means of micro-hardness and tensile tests. For the micro-harness evaluation, the average value of at least five points of randomly selection regions in each specimen is reported. The tensile behavior of extruded composites was measured (the average value of three samples) by using an Instron testing machine at a constant crosshead displacement rate of $0.36 \mathrm{~mm} / \mathrm{s}$. Pin-loaded tension test specimens with a gage length of $30 \mathrm{~mm}$ were prepared in accordance to the ASTM E8M standard. The yield strength $\left(\sigma_{\mathrm{y}}\right)$ was calculated on the basis of $\varepsilon=0.2 \%$ strain and the maximum strength $\left(\sigma_{\max }\right)$ at the maximum value of the $\sigma-\varepsilon$ curve.

\section{Results and Discussion}

\subsection{Morphology of the MWCNTs}

The MWCNTs were formed over the inner surface of quartz tube. Near the gas outlet a reddish film was observed, which denoted the oxidation of the iron precursor, probably as a consequence of oxygen diffusion from the atmosphere during the furnace cooling.
The conditions used in this experimentation were the adequate for successfully synthesize MWCNTs by the spray pyrolysis method. The formation of MWCNTs on the quartz tube surface had the appearance of a uniform thickness layer and length of around $1300 \mu \mathrm{m}$, as shown in Figure 3a. SEM observations at higher magnification (Figure 3b) allowed to discern that the MWCNTs layer consisted of highly agglomerated snake-like nanotubes with diameters of 55-120 nm.

TEM images of the as-synthesized MWCNTs are shown in Figure 4. Figure 4a shows more and well-defined CNTs with uniform wall thickness and smooth surfaces. The MWCNTs having multiwalled hollow structures possess few impurities, such as amorphous carbon shown in Figure $4 b^{24}$; this suggests that the purity of MWCNTs is sufficient for them to act as good reinforcing material in the following treatment without further purification ${ }^{25}$. Regular MWCNTs walls parallel to the axis direction can be clearly observed in Figure 4c; the interlayer spacing of MWCNTs were calculated to be $0.62 \mathrm{~nm}$ by the Digital Micrograph software image $\mathrm{PRO}^{\circledR}$.

The effect of the dry mixing on the dispersion of the CNTs was reported elsewhere ${ }^{26}$; according to these authors, clustering is a major problem due to the large difference in size between the aluminum particles (micrometers) and the nanotubes (nanometers). FESEM was employed to characterize the mixture before and after the ultrasonication (Figure 5). Figure 5a shows the mixture of A17075 particles and MWCNTs before the ultrasonication process, where the MWCNTs clustering is evident. Figure $5 \mathrm{~b}$ shows how the MWCNTs were dispersed among the particles after the ultrasonication and drying processes, which prevented the cluster formation. 


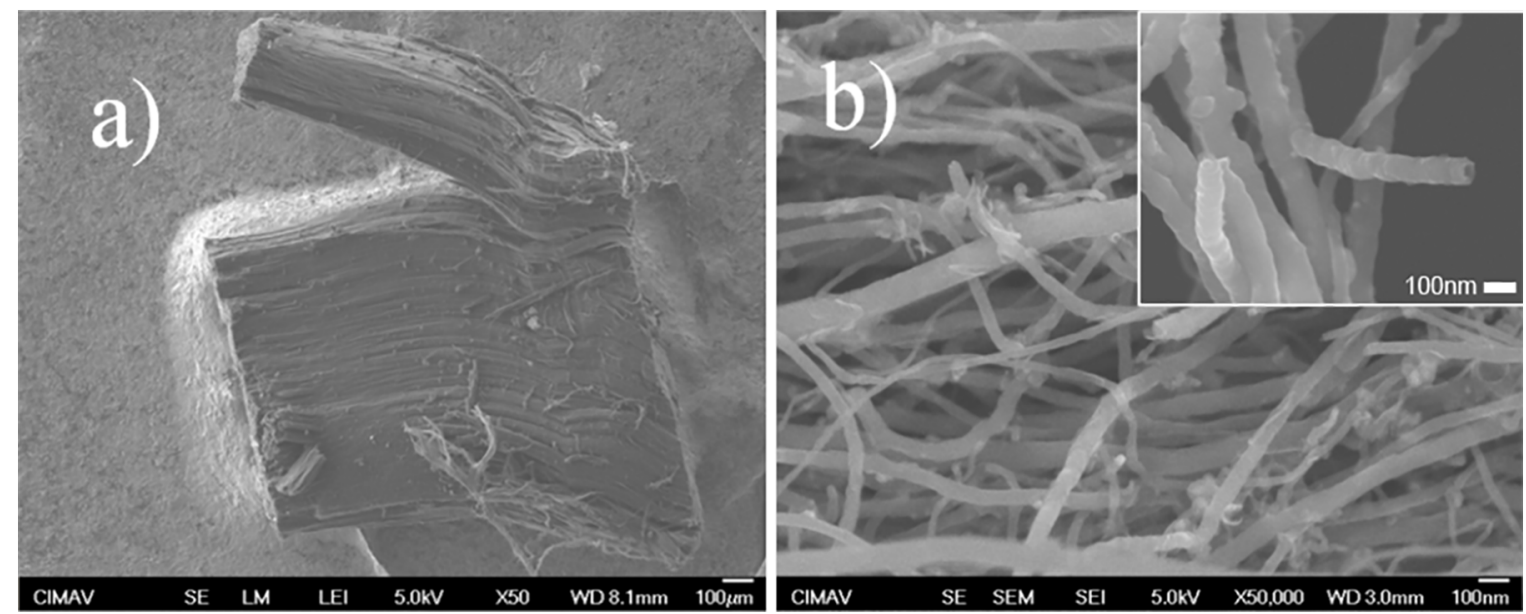

Figure 3. SEM images of MWCNTs formed by spray pyrolysis, showing their (a) length and (b) diameter.
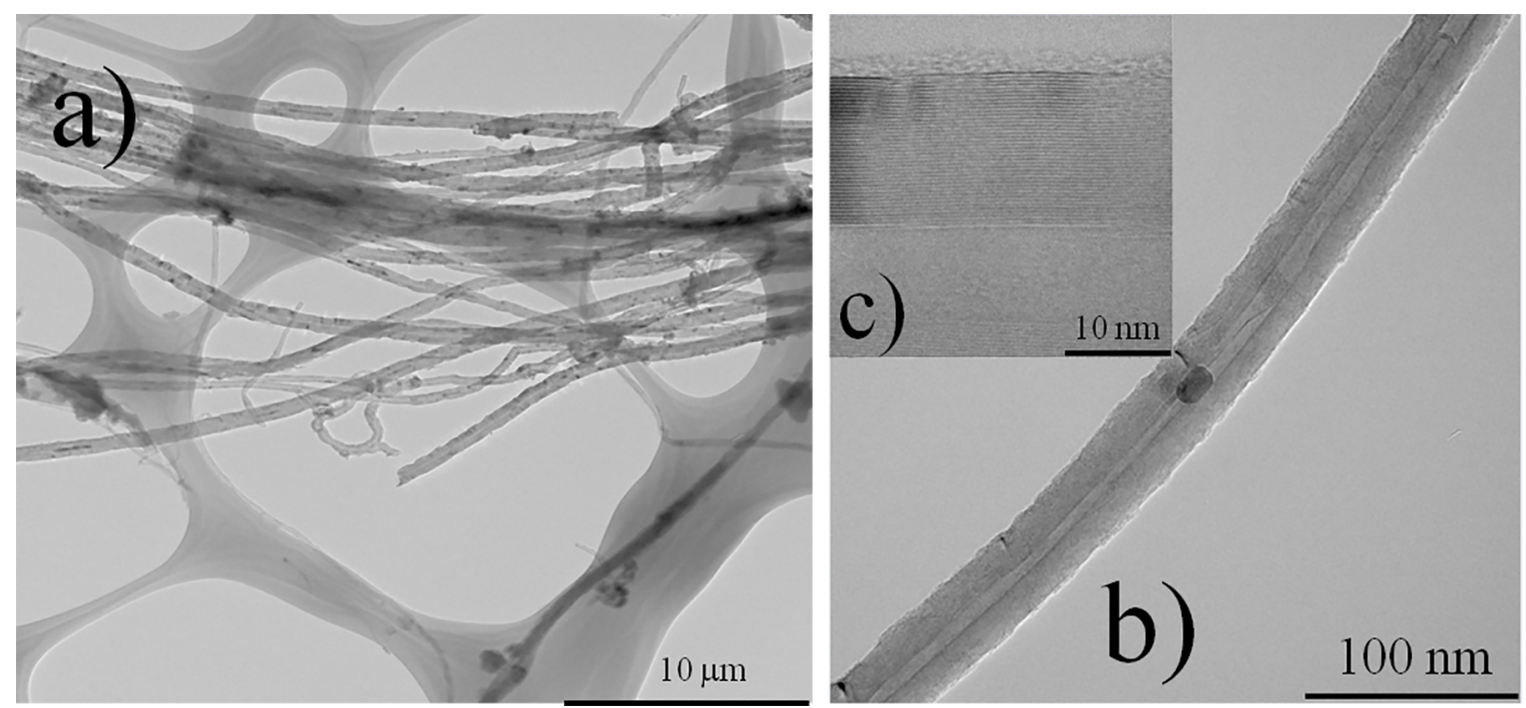

Figure 4. TEM images of the MWCNTs synthesized by spray pyrolysis.
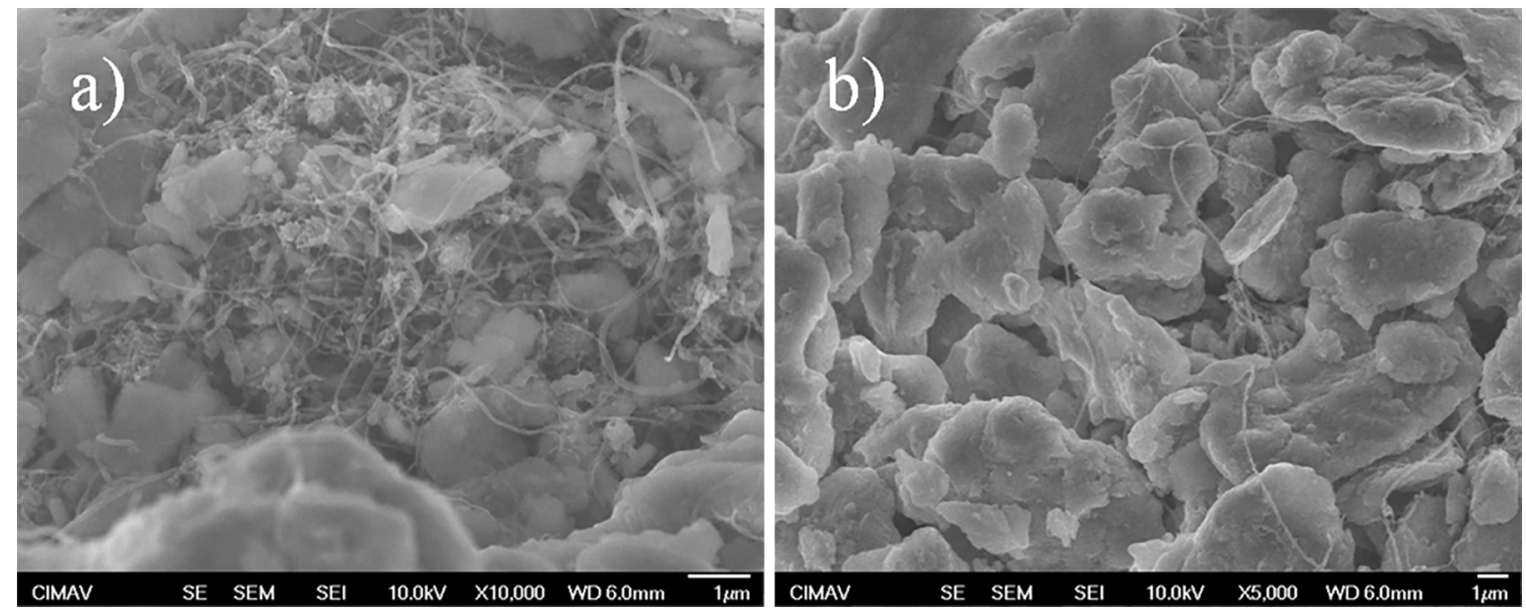

Figure 5. FESEM micrographs showing: a) clusters of MWCNTs mixed with A17075 particles before ultrasonication and b) MWNTCs dispersed in the A17075 particles after the ultrasonication and drying processes. 


\subsection{Microstructure of the MWCNTS/Al7075 composites}

The SEM technique was used to characterize the morphology and size of the milled composite powders and to investigate the effect of the MWCNTs concentration on their dispersion within the aluminum matrix. Figure 6 evidences that even though all samples were milled for $5 \mathrm{~h}$, there was a reduction of the particle size as the MWCNTs content was increased. Indeed, the diameter of composite powders with $3.0 \mathrm{wt} \%$ of MWCNTs ranged from 30 to 100 $\mu \mathrm{m}$ (Figure 6g), while the diameter of the Al7075 alloy $(0.0 \mathrm{wt} \%$ of MWCNTs) milled under the same conditions, ranged from 40 to $250 \mu \mathrm{m}$ (Figure 6a). This effect may be attributed to the fact that the MWCNTs are acting as a process control agent, minimizing the effect of cold welding and favoring the particle fracturing process. Results from Vickers hardness shown below are in accordance with the particle refinement behavior observed in Figure 6. Reduction in particle size is due to the increased presence of CNTs, which act as refiner by producing a harder surface of the particles after each impact from the milling media and therefore increasing their brittleness. Thus, during the milling process, where each particle undergoes constant cycles of fracture-welding-fracture ${ }^{27}$, external second phases in the case of CNTs, interfere with this cycle at the same time that they are being incorporated into the aluminum particles by making them harder each time. With the increasing content of CNTs the effect is maximized obtaining as a result a predominance of the fracture stage and harder and smaller particles, in accordance with the results observed in Figure 6 and in the mechanical properties, as will be discussed later.

It is important to analyze the distribution of the MWCNTs within the composite powders, particularly in that with the highest MWCNTs content. Figure 7 present a micrograph of the composite powder with $3.0 \mathrm{wt} \%$ of MWCNTs, where the MWCNTs can be observed well dispersed and deeply embedded in the A17075 matrix. This confirms that even with high MWCNTs concentration, a good dispersion of the reinforcing phase can be achieved by the whole process implemented in this work. Generally speaking, the distribution of the MWCNTs in the starting powder mixtures plays a crucial role on their homogeneous dispersion within the Al7075 matrix after milling. On the other hand, in Figure 7 it can be also seen that the MWCNTs appear intact after being subjected to the mechanical milling process.

\subsection{Mechanical properties}

The reinforcement fraction and matrix strength play a role in influencing the behavior of the composites under hardness and tensile loading conditions. The tensile strength of the A17075 and its composites as a function of the MWCNTs weight fraction is shown in Figure 8a. A positive slope in the tensile plot values is observed as the MWCNTs concentration increases. It can be observed that the peak strength $\left(\sigma_{\max }\right)$ of the tensile evaluation is reached at $2.5 \mathrm{wt} \%$ of MWCNTs, which depicts a tensile value of $533 \mathrm{MPa}$. In comparison with the reference alloy (A17075-O) ${ }^{28}$, the composite 2.5-MWCNTs/ A17075 shows an increment of $133 \%$. This increment in the tensile performance is due to the synergic contribution of the milling process and the MWCNTs presence in the composite. In addition, an increment of $37 \%$ is observed in the 2.5-MWCNTs/A17075 composite when comparing with the milled 0.0-MWCNTs/A17075 composite. This increment in the tensile strength can be attributed to the individual effect produced by the MWCNTs in the composite. Figure $8 \mathrm{~b}$ presents the results for the yield strength, where an increase in the yield strength $\left(\sigma_{y}\right)$ of the MWCNTs/Al composites is seen, compared to the milled and the reference Al7075-O alloys. The $\sigma_{\mathrm{y}}$ increases up to $25 \%$ for the sample with 2.0 $\mathrm{wt} \%$ of MWCNTs, in comparison with the $0.0-\mathrm{MWCNTs} /$ A17075 sample.

Figure 9a shows the elongation behavior observed under tensile conditions as a function of the MWCNTs concentration. A negative tendency in the plot is observed as the MWCNTs content increases. The decrement in the elongation behavior is directly related with the hardness and tensile behavior observed in Figure 8. Nevertheless, it can be observed that the milled Al7075 alloy (0.0-MWCNTs/A17075) presents a remarkable increment in the elongation in comparison with the unmodified alloy (A17075-O). Although the 2.5-MWCNTs/ A17075 and the 3.0-MWCNTs/A17075 composites present a similar elongation to that of the reference commercial alloy, their maximum and yield strengths have been improved, as can be observed in Figure 8.

A similar trend in the hardness behavior of composites can be observed in Figure 9b. The maximum hardness value was obtained at the maximum concentration of MWCNTs. The plot shows a rapid increase in the hardness value with the first additions of MWCNTs. A further increase in the nanotubes content leads to a noticeable increment in the hardness values reaching a maximum value above 160 Vickers hardness units. The increment in the hardness values is due to the presence of the MWCNTs homogeneously distributed along the aluminum matrix, producing an improved resistance to load transfer. The interaction of MWCNTs with dislocations and their density are additional strengthening mechanisms that must be considered in the mechanical performance of the composites.

\subsection{Microfractography}

Fractographies of the composites with 2.0 and 3.0 $\mathrm{wt} \%$ of MWCNTs are presented in Figure 10. A ductile fracture is observed, which indicates a strong bond between milled particles. MWCNTs appear well embedded into the aluminum matrix. The homogeneous dispersion of nanotubes observed in Figure 7 remains after sintering and subsequent processing conditions used in the production of 

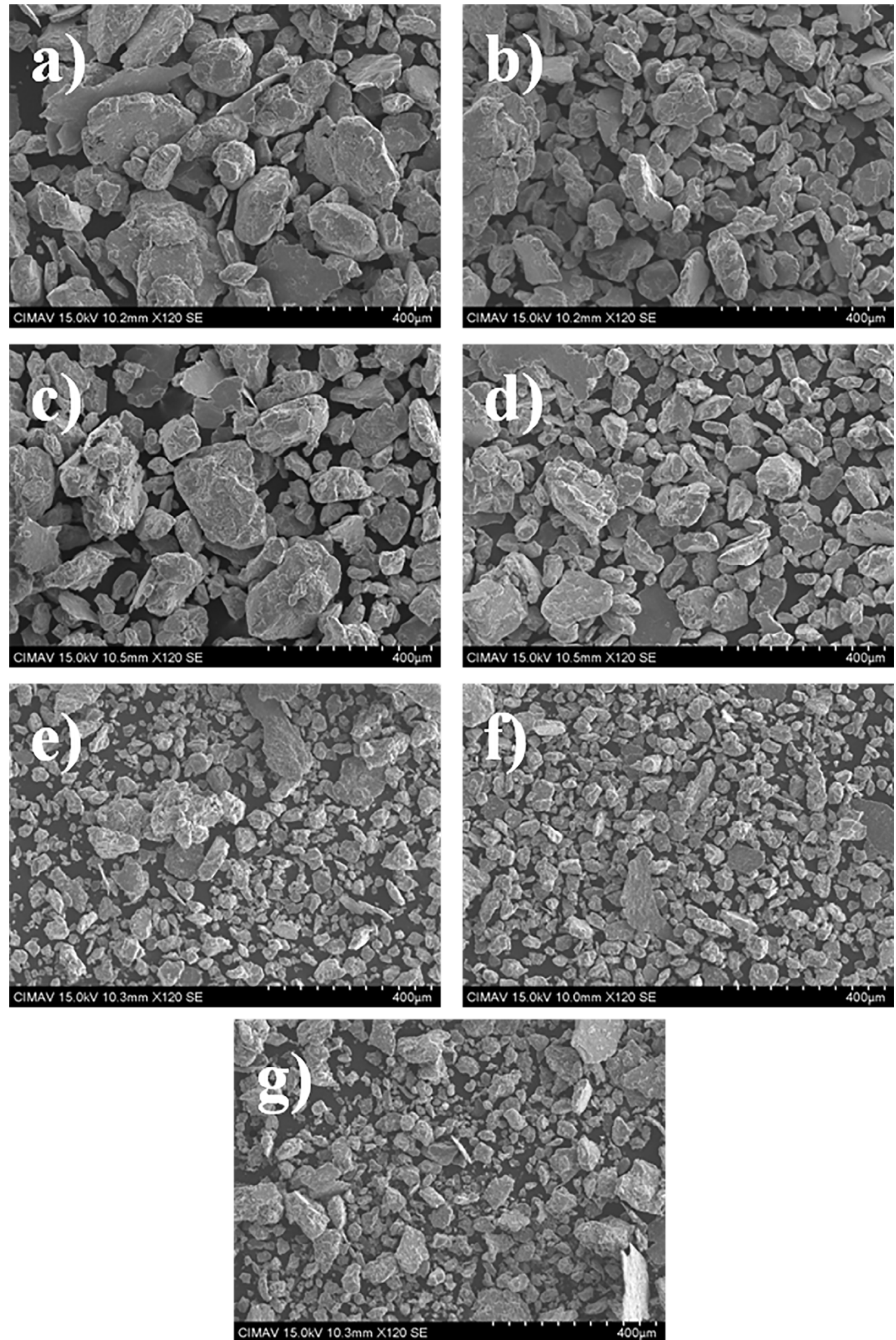

Figure 6. SEM micrographs of the A17075/MWCNTs composite powders milled for $5 \mathrm{~h}$ as a function of the MWCNTs content: (a) 0.0 , (b) 0.5 , (c) 1.0 , (d) 1.5 , (e) 2.0 , (f) 2.5 and (g) $3.0 \mathrm{wt} \%$. 
the composites. Under the FESEM observation conditions, MWCNTs do not present visible damage produced during the milling process (Figure 10b), which corroborates that

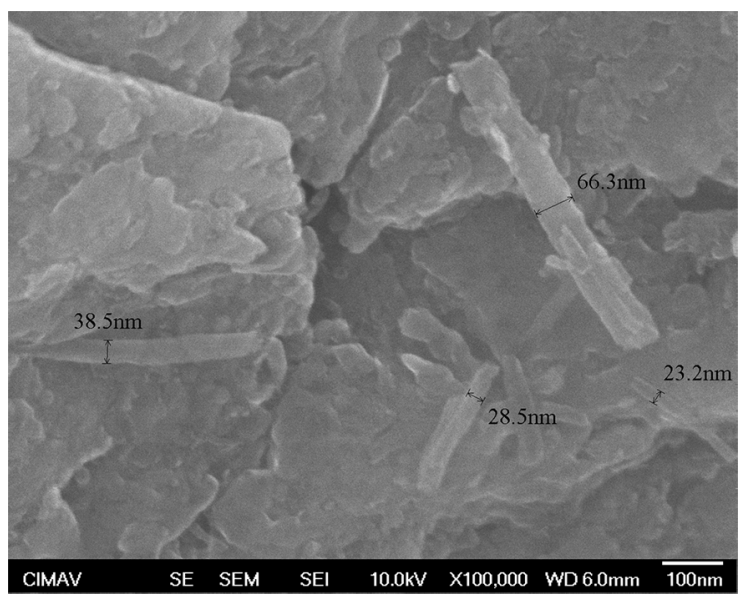

Figure 7. Micrograph of the $3.0 \mathrm{wt} \%$ MWCNTs composite powder after $5 \mathrm{~h}$ of milling.

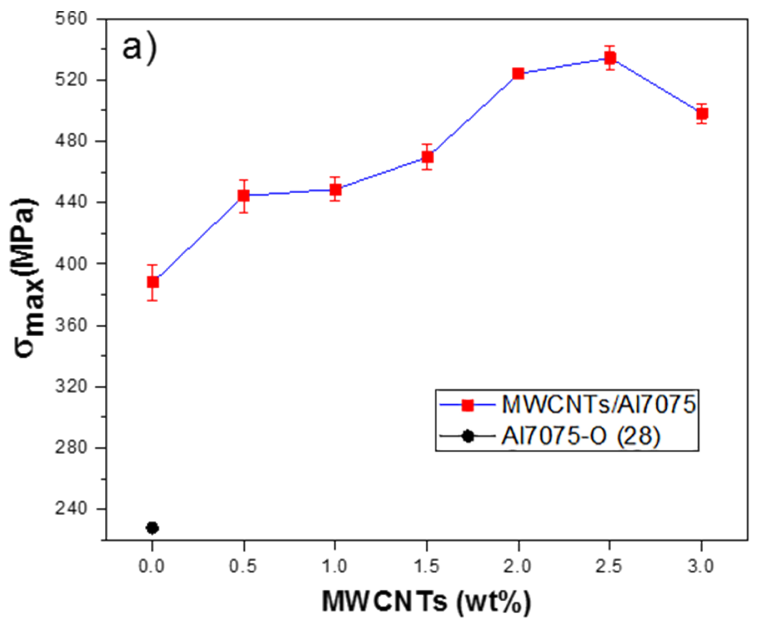

sintering and hot extrusion do not produce visible alterations on the MWCNTs morphology.

The improvement in the mechanical behavior shown after mechanical tests gives proof of the excellent affinity between the aluminum matrix and the nanotubes, which form strong mechanical bonds and an effective load transfer mechanism of the composites that can be explained by several theories. First of all, even though TEM micrographs do not display the effect of the CNTs on the grain size, SEM micrographs give proof of the effectiveness of the CNTs on the reduction of particle size. This reduction on particle size is produced by hard particles, whose hardness increases as the CNT content increases as well, causing a predominance of the fracture stage during the mechanical milling process ${ }^{27}$. In this regard, an increased amount of dislocations is continuously generated due to continuous cycles of cold deformation produced during the milling process. This process generates an increased amount of dislocations, which are continuously piled up due to the presence of obstacles as in the case of the CNTs, which inhibits their motion producing as a consequence a harder material ${ }^{29}$. Additional strengthening

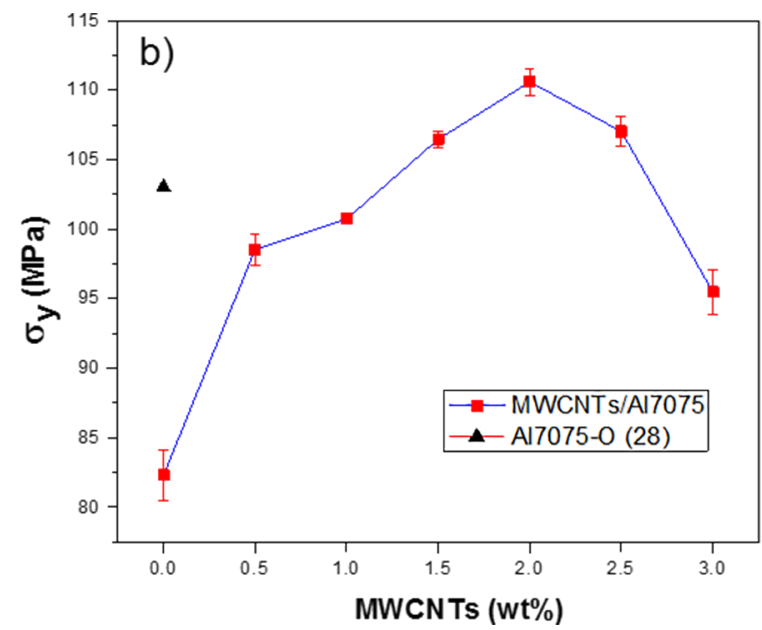

Figure 8. (a) Tensile and (b) yield strength behavior of the A17075 and its composites.
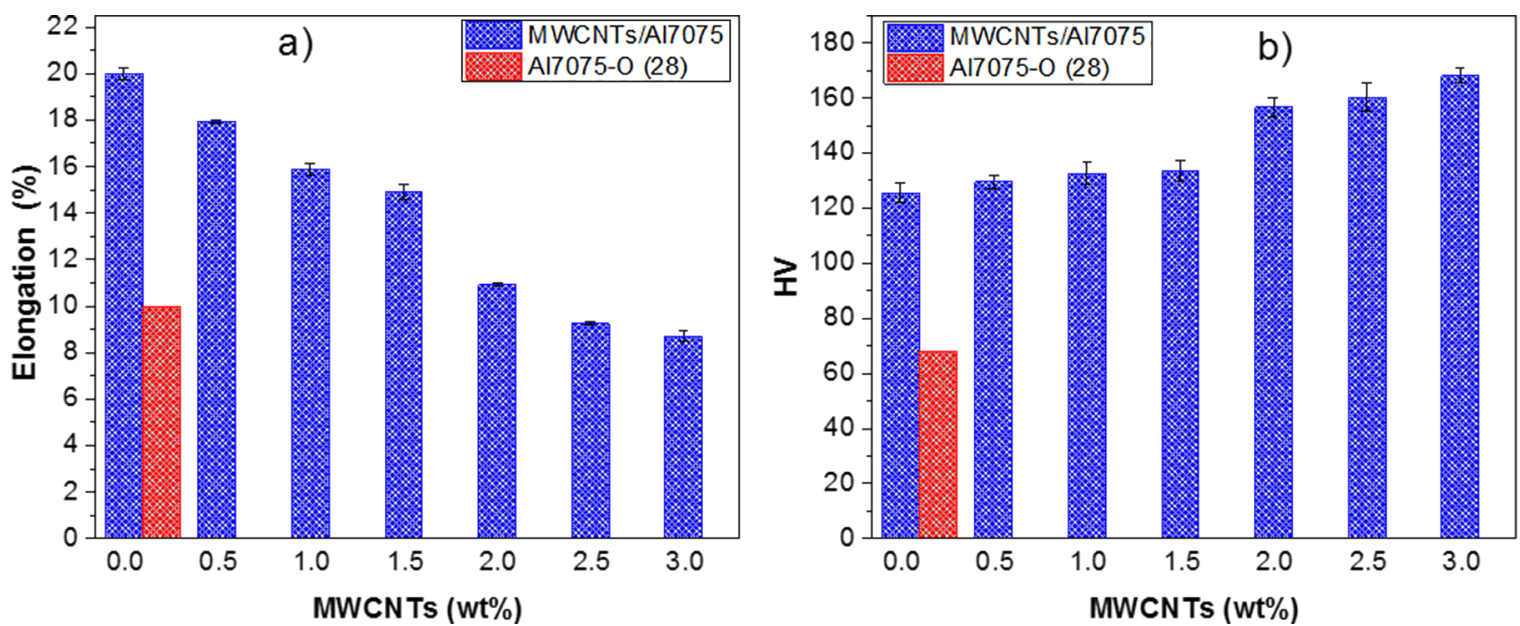

Figure 9. (a) Elongation and (b) hardness results of the Al7075 and its composites. 

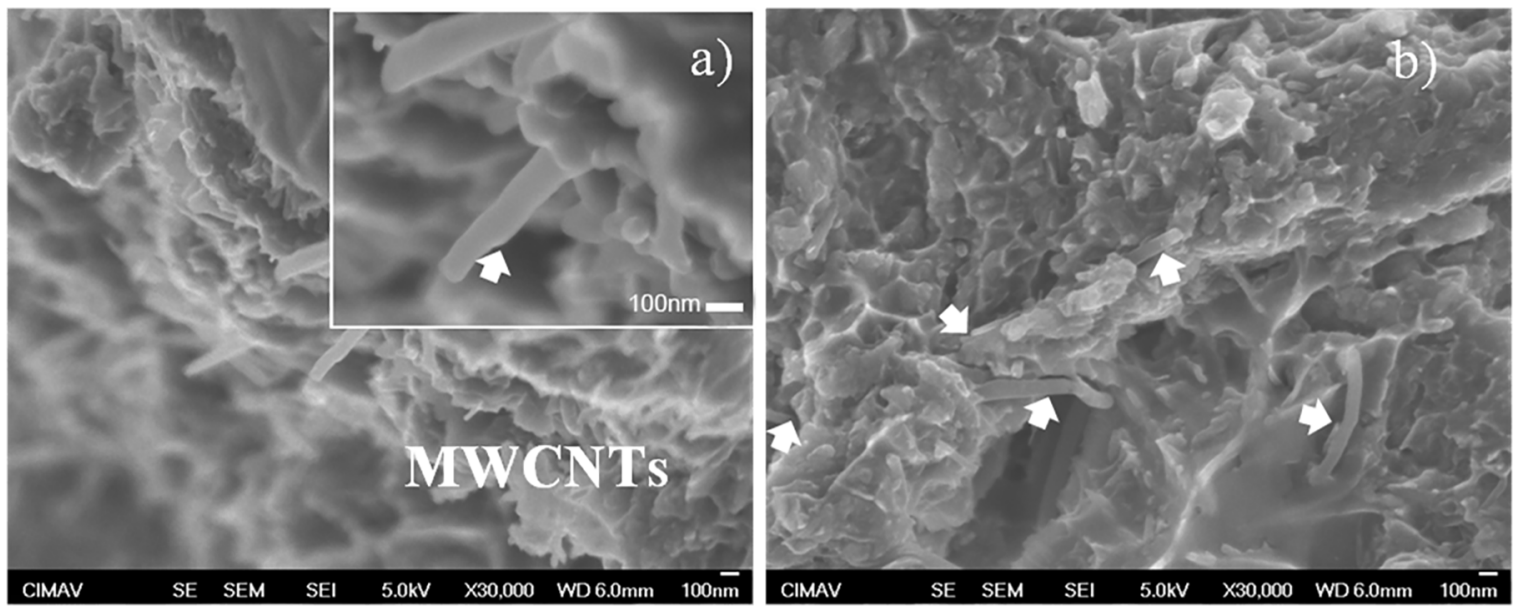

Figure 10. FESEM fractographs of MWCNTs/A17075 composites with (a) 2.0 and (b) $3.0 \mathrm{wt} \%$ MWCNTs.

mechanisms must be considered in order to fully understand the mechanical behavior of CNTs/aluminum composites, and additional work must be carried out. Thus, strengthening mechanisms such as wetting of CNTs by the aluminum matrix and thermal mismatch between both phases are hypothesis to be considered.

\section{Conclusions}

Spray pyrolysis of the ferrocene/toluene mixture was successfully used to produce MWCNTs. Samples consisted of multiple layers of rolled graphene in on themselves forming a tube shape with lengths up to $1300 \mu \mathrm{m}$ and diameters from 55 to $120 \mathrm{~nm}$. The MWCNTs produced had a few impurities, which allowed them to be incorporated into the A17075 matrix without a previous purification treatment.

A major issue in the development of MWCNTs/A17075 composites is the agglomeration of the reinforcement into the matrix. It was demonstrated that the ultrasonication process and mechanical milling are an effective combination of techniques that can be used to solve this problem.

It was demonstrated that the increment in the MWCNTs content is a way to reduce the excessive particle welding during the milling process, with which lower particle sizes were achieved for the same milling time.

SEM analysis revealed MWCNTs well dispersed and deeply embedded in the A17075 matrix, with not damage after the severe conditions reached with the mechanical milling process.

The tensile and yield strengths of composites were higher in all composites, but with the inherent decrease in ductility as the reinforcing material was added. Despite this, composites with $0.5 \mathrm{wt} \%$ to $2 \mathrm{wt} \%$ of MWCNTs showed a good ductility.

MWCNTs/A17075 composites have shown higher microhardness when compared to the hardness of A17075 alloy and commercial A17075-O alloy. Further, microhardness of composites increased with the increase of the reinforcement content.

\section{Acknowledgements}

The Authors of this paper thank to Red Temática de Nanociencias y Nanotecnología and Red Temática de Ciencia y Tecnología del Espacio. The authors gratefully acknowledge the efforts of D. Lardizabal-Gutierrez, W. Antunez-Flores, K. Campos-Venegas, R. Castañeda-Balderas and R. OchoaGamboa for their technical assistance.

\section{References}

1. Herrera-Ramirez JM, Perez-Bustamante R, Aguilar-Elguezabal A. An Overview of the Synthesis, Characterization, and Applications of Carbon Nanotubes. In: Yaragalla S, Mishra R, Thomas S, Kalarikkal N, Maria HJ, eds. Carbon-Based Nanofillers and their Rubber Nanocomposites: Carbon Nano-Objets. 1st ed. Cambridge: Elsevier. 2018. p. 47-75.

2. Bethune DS, Klang CH, de Vries MS, Gorman G, Savoy R, Vazquez J, et al. Cobalt-catalysed growth of carbon nanotubes with single-atomic-layer walls. Nature. 1993;363(6430):605607.

3. Singh C, Shaffer MSP, Koziol KKK, Kinloch IA, Windle AH. Towards the production of large-scale aligned carbon nanotubes. Chemical Physics Letters. 2003;372(5-6):860-865.

4. Liu BC, Lee TJ, Lee SH, Park CY, Lee CJ. Large-scale synthesis of high-purity well-aligned carbon nanotubes using pyrolysis of iron(II) phthalocyanine and acetylene. Chemical Physics Letters. 2003;377(1-2):55-59.

5. Lee CJ, Lyu SC, Kim HW, Park CY, Yang CW. Large-scale production of aligned carbon nanotubes by the vapor phase growth method. Chemical Physics Letters. 2002;359(1-2):109114.

6. Harris PJF. Carbon Nanotube Science: Synthesis, Properties and Applications. New York: Cambridge University Press; 2009. 
7. Tjong SC. Recent progress in the development and properties of novel metal matrix nanocomposites reinforced with carbon nanotubes and graphene nanosheets. Materials Science and Engineering: R: Reports. 2013;74(10):281-350.

8. Thostenson ET, Ren Z, Chou TW. Advances in the science and technology of carbon nanotubes and their composites: a review. Composites Science and Technology. 2001;61(13):1899-1912.

9. Tjong SC. Structural and mechanical properties of polymer nanocomposites. Materials Science and Engineering: R: Reports. 2006;53(3-4):73-197.

10. Isaza M CA, Ledezma Sillas J, Meza JM, Herrera Ramírez JM. Mechanical properties and interfacial phenomena in aluminum reinforced with carbon nanotubes manufactured by the sandwich technique. Journal of Composite Materials. 2017;51(11):1619-1629.

11. Carreño-Gallardo C, Uriza-Vega E, Estrada-Guel I, HerreraRamírez M, Martínez-Sánchez R, López-Meléndez C, et al. Effect of Multiwall Carbon Nanotubes (MWCNs) Reinforcement on the Mechanical Behavior of Synthesis 7075 Aluminum Alloy Composites by Mechanical Milling. Microscopy and Microanalysis. 2017;23(Suppl S1):1930-1931.

12. Guo B, Ni S, Yi J, Shen R, Tang Z, Du Y, et al. Microstructures and mechanical properties of carbon nanotubes reinforced pure aluminum composites synthesized by spark plasma sintering and hot rolling. Materials Science and Engineering: A. 2017;698:282-288.

13. Aranke O, Gandhi C, Dixit N, Kuppan P. Influence of Multiwall Carbon Nanotubes (MWCNT) on Wear and Coefficient of Friction of Aluminium (Al 7075) Metal Matrix Composite. MaterialsToday: Proceedings. 2018;5(2 Pt 2):7748-7757.

14. Bakshi SR, Lahiri D, Agarwal A. Carbon nanotube reinforced metal matrix composites - a review. International Materials Reviews. 2010;55(1):41-64.

15. Bakshi SR, Agarwal A. An analysis of the factors affecting strengthening in carbon nanotube reinforced aluminum composites. Carbon. 2011;49(2):533-544.

16. Tokunaga T, Kaneko K, Horita Z. Production of aluminummatrix carbon nanotube composite using high pressure torsion. Materials Science and Engineering: A. 2008;490(1-2):300304.

17. Liu ZY, Xiao BL, Wang WG, Ma ZY. Singly dispersed carbon nanotube/aluminum composites fabricated by powder metallurgy combined with friction stir processing. Carbon. 2012;50(5):1843-1852.
18. Jiang L, Li Z, Fan G, Cao L, Zhang D. The use of flake powder metallurgy to produce carbon nanotube (CNT)/aluminum composites with a homogenous CNT distribution. Carbon. 2012;50(5):19931998.

19. Wei H, Li Z, Xiong DB, Tan Z, Fan G, Qin Z, et al. Towards strong and stiff carbon nanotube-reinforced high-strength aluminum alloy composites through a microlaminated architecture design. Scripta Materialia. 2014;75:30-33.

20. Kwon H, Estili M, Takagi K, Miyazaki T, Kawasaki A. Combination of hot extrusion and spark plasma sintering for producing carbon nanotube reinforced aluminum matrix composites. Carbon. 2009;47(3):570-577.

21. He C, Zhao N, Shi C, Du X, Li J, Li H, et al. An Approach to Obtaining Homogeneously Dispersed Carbon Nanotubes in $\mathrm{Al}$ Powders for Preparing Reinforced Al-Matrix Composites. Advanced Materials. 2007;19(8):1128-1132.

22. Yang X, Liu E, Shi C, He C, Li J, Zhao N, et al. Fabrication of carbon nanotube reinforced $\mathrm{Al}$ composites with well-balanced strength and ductility. Journal of Alloys and Compounds. 2013;563:216-220.

23. Aguilar-Elguézabal A, Antúnez W, Alonso G, Delgado FP, Espinosa F, Miki-Yoshida M. Study of carbon nanotubes synthesis by spray pyrolysis and model of growth. Diamond and Related Materials. 2006;15(9):1329-1335.

24. Barreiro A, Kramberger C, Rümmeli MH, Grüneis A, Grimm D, Hampel S, et al. Control of the single-wall carbon nanotube mean diameter in sulphur promoted aerosol-assisted chemical vapour deposition. Carbon. 2007;45(1):55-61.

25. Vasileiou AA, Kontopoulou M, Gui H, Docoslis A. Correlation between the Length Reduction of Carbon Nanotubes and the Electrical Percolation Threshold of Melt Compounded Polyolefin Composites. ACS Applied Materials \& Interfaces. 2015;7(3):16241631.

26. Esawi A, Morsi K. Dispersion of carbon nanotubes (CNTs) in aluminum powder. Composites Part A: Applied Science and Manufacturing. 2007;38(2):646-650.

27. Suryanarayana C. Mechanical alloying and milling. Progress in Materials Science. 2001;46(1-2):1-184.

28. MatWeb Material Property Data. Aluminum 2024-T6. Available from: $<$ http://www.matweb.com/search/DataSheet.aspx?MatGU $\mathrm{ID}=\mathrm{ecf} 8530875 \mathrm{cb} 4 \mathrm{ded} 9675 \mathrm{~b} 827 \mathrm{f} 77 \mathrm{bfac} 5 \& \mathrm{ckck}=1>$. Access in: $22 / 9 / 2018$

29. George R, Kashyap KT, Rahul R, Yamdagni S. Strengthening in carbon nanotube/aluminium (CNT/Al) composites. Scripta Materialia. 2005;53(10):1159-1163. 